\title{
REPRODUKSI LAGU KR. KEMAYORAN: KONSTRUKSI SUBJEKTIVITAS NYAK INA RASEUKI (UBIET)
}

\author{
Susi Gustina ${ }^{1}$
}

\begin{abstract}
This article shows the knowledge and cultural perception of an Indonesian woman singer, Nyak Ina Raseuki (Ubiet), that was achieved through her musical experiences in social life and constructed her singing style as her aesthetic mastery (connoisseur). Her singing style is used to reproduce songs from the variety of musical genres so that constructed her subjectivity in Indonesian popular music. One of the songs is analyzed in this article is $K r$. Kemayoran, a song in the genre of keroncong. The research questions focus on 1) the construction of knowledge and cultural perception of Ubiet to construct her subjectivity, and 2) Ubiet's way to explore Kr. Kemayoran so that showed the difference from others. This research used the life history method to understand Ubiet's knowledge and cultural perception and the critical musicology to analyze the song. The research findings are the connoisseur is not depend only on formal education, but on the variety of musical practices in Ubiet's life. Besides it, Ubiet's subjectivity more focused on her musical competencies, i.e. her wide vocal range, the ability to explore many songs with microtones, local ornaments, as well as her ability to follow the development of meter and tonalilty (modulation) that are preceded by the music accompaniment.
\end{abstract}

Keyword: subjectivity, connoisseur, knowledge, cultural perception

\section{Pendahuluan}

Perbedaan dalam pertunjukan musik sebenarnya tidak hanya dilakukan oleh penyanyi perempuan, tetapi juga oleh penyanyi laki-laki. Namun, fakta memperlihatkan bahwa penonton atau pengamat musik umumnya akan lebih memberi perhatian pada perempuan daripada laki-laki atau pada femininitas ${ }^{2}$ daripada maskulinitas. Hal ini bukan berarti maskulinitas tidak ditampilkan, tetapi diasumsikan bahwa penonton akan lebih memperhatikan perempuan daripada laki-laki. Kenyataan ini dikemukakan oleh

\footnotetext{
1 Penulis adalah mahasiswa S3 (2007) di Program Studi Kajian Seni Pertunjukan dan Seni Rupa, Universitas Gadjah Mada, dengan topik disertasi Performativitas Penyanyi Perempuan dalam Pertunjukan Musik: Subjektivitas dan Femininitas Tiga Penyanyi Indonesia dengan Tim Promotor yang terdiri dari Prof. Dr. Timbul Haryono, M.Sc., Dr. Lono L. Simatupang, M.A., dan Prof. Drs. Triyono Bramantyo, M.Mus., Ed., Ph.D.

2 Maggie Humm (2002), dalam bukunya Ensiklopedia Feminisme, menjelaskan bahwa femininitas merupakan istilah yang mendeskripsikan konstruksi 'keperempuanan' oleh masyarakat dan mempunyai konotasi daya tarik seksual bagi laki-laki.
} 
Tonje Håkensen (2007) bahwa, "this does not mean that masculinity is not performed, but that it traditionally has been assumed that women are more mannered in their actions than men are". Walaupun feminisme dan perubahan dalam masyarakat umumnya telah membatasi asumsi-asumsi seperti itu, beberapa faktor tetap memperlihatkan bagaimana femininitas tetap dipandang lebih artifisial, lebih khusus, daripada maskulinitas.

Salah satu alasan mengapa penyanyi perempuan lebih diperhatikan daripada laki-laki adalah karena penyanyi perempuan terkesan lebih dibuat-buat atau artifisial. Mengenai hal ini Judith Halberstam (dalam Jarman - Ivens, 2004) pernah menjelaskan bahwa,

as a result of how masculinity historically has been the norm of humanity - that the male subject has been considered beyond definition, femininity is more related to the artificial and the performative than masculinity is.

Mengikuti pemikiran Halberstam itu dapat dikatakan bahwa maskulinitas secara historis menjadi norma humanitas, yaitu bahwa subjek laki-laki dipandang ada dalam definisi itu. Dibandingkan maskulinitas, femininitas lebih dihubungkan dengan masalah artifisial dan performatif melalui kostum, make-up, tatanan rambut, dan asesoris yang digunakan penyanyi perempuan.

Penyanyi perempuan seolah-olah menyadari keberadaan mereka dalam pertunjukan musik. Umumnya, para penyanyi tersebut akan tampil feminin sesuai dengan harapan penonton. Lucy Green (dalam O'Shea, 2008) menyebut fenomena ini sebagai pertunjukan feminin (feminine performance). Mengenai pertunjukan feminin, Iris Marion Young (dalam O’Shea, 2008) pernah menegaskan:

women's acute awareness of their bodies and their need to look 'right' for the masculine gaze (including its refraction through the eyes of other women) with women's sense of space as not their own, where they are objects to be looked at.

Kesadaran penyanyi perempuan untuk tampil feminin sesuai dengan harapan penonton tersebut memperkuat keberadaan penyanyi perempuan sebagai objek pandang dalam pertunjukan musik, khususnya laki-laki. 
Kenyataan ini tidak hanya terjadi dalam pertunjukan musik di negara Barat, tetapi juga di negara-negara lainnya, termasuk Indonesia. Penyanyi perempuan dalam pertunjukan musik populer seolah-olah memahami keberadaan mereka sebagai objek pandang penonton. Tidak dapat dipungkiri bahwa mereka akan selalu mempertimbangkan penampilan visual dalam pertunjukan musik. Salah seorang personil kelompok band perempuan di Indonesia, She, misalnya, pernah menjelaskan tentang penampilan mereka dalam pertunjukan musik bahwa, kita gak hanya menjual suara, tapi menjual bentuk. ... Kita bisa saja sih gak dandan waktu nampil seperti band cowok, tapi gak bisa karena kita sadar kita perempuan"”. Namun, kenyataan menunjukkan bahwa tidak seluruh penyanyi perempuan melakukan hal yang sama. Salah satunya penyanyi perempuan tersebut adalah Nyak Ina Raseuki, yang seringkali dipanggil Ubiet.

Berbeda dari umumnya penyanyi perempuan dalam arus utama musik populer di Indonesia yang berorientasi pada gaya modern a la Barat, Ubiet dikenal sebagai seorang penyanyi perempuan yang memiliki gaya bernyanyi yang melibatkan ornamenornamen lokal. Berdasarkan gaya bernyanyinya yang unik, Ubiet sering disebut sebagai penyanyi perempuan dengan gaya nyanyi berornamen. Kegemarannya melakukan eksplorasi suara menyebabkan pandangan beberapa penonton yang menyebutnya sebagai 'pesuara'. Masyarakat mengenalnya tidak hanya sebagai penyanyi, tetapi juga etnomusikolog yang seringkali melakukan penelitian tentang musik pada masyarakat lokal. Ia juga dikenal sebagai penyanyi perempuan yang sering mereproduksi lagu-lagu dari beragam genre musik. Salah satunya adalah mereproduksi lagu-lagu keroncong. Melalui gaya bernyanyinya yang unik, Ubiet mereproduksi lagu secara berbeda dari penyanyi keroncong lainnya dalam menyanyikan lagu yang sama.

Ironisnya, pengalaman musikalnya yang beragam, musikalitas dan kreativitasnya yang jarang dimiliki oleh umumnya penyanyi perempuan, serta gaya bernyanyinya yang unik tersebut justru tidak menarik perhatian industri musik untuk meningkatkan popularitasnya dalam musik populer di Indonesia. Kenyataan memperlihatkan bahwa Ubiet jarang sekali tampil dalam acara-acara hiburan di televisi swasta maupun pemerintah. Kehadirannya dalam pertunjukan musik justru didukung oleh pemilik modal kultural yang menghargai kreativitasnya sebagai penyanyi atau

\footnotetext{
${ }^{3}$ Wawancara dalam salah satu acara infotainment yang disiarkan oleh salah satu televisi swasta nasional pada 12 November 2007.
} 
musisi. Dukungan industri terhadap kreativitas Ubiet sebagai penyanyi perempuan pernah dilakukan oleh Warner Music Indonesia (WMI) dalam mendistribusikan album rekamannya, Archipelagongs (2000), yang merupakan kolaborasinya dengan Dotty Nugroho dan Sekar Ayu Asmara. Album ini dipandang sebagai kreasi musik pop 'lain' Indonesia, atau dapat dikatakan sebagai aliran new age (abad baru) (Newsmusik, 2000). Ubiet berperan dalam merancang garis melodi dasar dan ornamentasi untuk vokalnya sendiri. Seluruh lagu yang terdapat dalam album ini memiliki ornamentasi yang sesuai dengan landasan etnik dari beberapa budaya di Indonesia.

Sayangnya, album rekaman tersebut diproduksi dalam jumlah terbatas. Bahkan, video clip dua lagu dalam album tersebut, Keumalahayati dan Gates of Puya, yang disutradarai oleh Jay Subyakto dan Dimas Djajadiningrat secara artistik, gagal disosialisasikan melalui media televisi swasta. Mengenai fakta ini, Subyakto ${ }^{4}$, menyatakan:

video itu jarang sekali ada di TV swasta sekitar tahun 2000 karena produsernya, ... (Jay menyebut nama seorang produser di Indonesia penulis), sangat 'pelit' dan sama sekali tidak berinisiatif untuk memasarkan album tersebut. Ini sangat mengherankan. Tapi, memang begitulah mental produser CD dan kaset di Indonesia, khususnya, dalam menyikapi album non-pop yang sejenis album Ubiet. Sebagai akibatnya, jarang sekali muncul album-album eksperimen yang mengacu ke akar musik Indonesia karena keberadaannya justru dimatikan oleh para produser dan juga pemerintah yang tidak berbuat apa-apa untuk kemajuan musik Indonesia".

Senada dengan pernyataan Subyakto, ini Ubiet mengemukakan pandangannya sebagai berikut,

ya itu... orang takut dengan perbedaan. Sesuatu yang berbeda adalah salah. Album itu sebenarnya jenis pop, tapi yang di luar biasanya. Kita maunya masyarakat menghargai perbedaan. Capek aku ngomong seperti ini. Sudah malas. Sekarang, aku hanya berbuat saja. Maksudnya, gak ingin orang harus dengerin musik kita. Buat apa? Kalau mau berbuat, berbuat saja lah. Gak usah mengharapkan apa-apa... .5

Pernyataan Ubiet di atas memperlihatkan idealismenya sebagai musisi atau penyanyi yang lebih mementingkan kreativitas daripada popularitas dalam industri

\footnotetext{
${ }^{4}$ Pernyataan melalui email pada 10 September 2009.

${ }^{5}$ Wawancara dilakukan di Dharmawangsa Plaza, Jakarta, pada 14 Juli 2010.
} 
musik. Kenyataan ini secara jelas memperlihatkan perbedaan atau subjektivitasnya sebagai penyanyi perempuan yang berbeda dari penyanyi perempuan lain yang memilih 'tunduk' kepada keinginan industri musik sebagai upaya untuk memperoleh popularitas dan keuntungan finansial, yaitu lebih mengutamakan representasi tubuh. Salah satu upaya dalam mengkonstruksi subjektivitasnya adalah menerapkan gaya bernyanyinya yang unik dalam mereproduksi lagu Kr. Kemayoran pada album Ubiet: Kroncong Tenggara (Ragadi Musik, 2007).

Kemampuan Ubiet untuk mereproduksi lagu Kr. Kemayoran tersebut tidak dapat dilepaskan dari pengetahuan dan wawasan kultural yang diperoleh Ubiet dalam proses kehidupannya dalam lingkungan sosial, sejak kanak-kanak hingga dewasa. Berdasarkan asumsi tersebut maka dalam tulisan ini dikemukakan beberapa pertanyaan, yaitu:

1. Bagaimana konstruksi pengetahuan dan wawasan kultural yang dialami Ubiet sehingga ia mampu mengkonstruksi subjektivitasnya dalam pertunjukan musik?

2. Bagaimana Ubiet mengeksplorasi lagu Kr. Kemayoran sehingga membedakannya dari penyanyi lain dalam musik populer?

Untuk memahami kajian secara kontekstual, perspektif yang digunakan dalam penelitian ini adalah perspektif feminis postrukturalis yang menekankan pada kekhususan historis dan budaya dalam beragam pengalaman yang diperoleh penyanyi perempuan dalam lingkungan sosial (Brooks, 1997). Untuk memahami fokus kajian maka penelitian ini menggunakan metode life-history (Marshall dan Rossman, 2006; Abdullah, 2003). Life history merupakan salah satu bentuk analisis naratif yang memungkinkan seluruh rangkaian pengalaman subjektif artis perempuan dikonstruksi secara mendalam. Penggunaan metode life-history dalam kajian yang memfokuskan pada femininitas artis perempuan dalam pertunjukan musik merupakan hal penting untuk dilakukan untuk memahami "apa maunya" mereka atau "suara" artis perempuan (Abdullah, 2003). Kajian seperti ini dipandang dapat lebih memperlihatkan sesuatu yang riil dan justru dapat menjelaskan isu keragaman subjektivitas penyanyi perempuan dalam musik populer.

Untuk memahami 'suara' atau sudut pandang penyanyi perempuan secara tekstual, penulis menggunakan perspektif musikologi kritik (critical musicology) dalam 
analisis data. Allan F. Moore (2003) menjelaskan bahwa perspektif musikologi kritik (critical musicology) dari beberapa dekade terakhir ditandai dengan suatu pendekatan relativis dan interdisipliner yang menempatkan perspektif ini di dalam metode ilmiah postrukturalis. Moore mengkritisi musikologi populer yang biasanya dilakukan oleh para musikolog di masa sebelumnya bahwa, "the most central problem within popular musicology has become the question of the text; how it is defined and how it should be analyzed". Masalah paling utama di dalam musikologi populer adalah mempermasalahkan teks, yaitu bagaimana teks didefinisikan dan bagaimana teks dianalisis.

Musikologi populer hanya melibatkan analisis pengalaman musikal analis atau peneliti sendiri. Moore menyimpulkan bahwa, "since any analysis is an interpretation of what elements are most significant in a piece of music, the object of analysis is the analyst's musical experience", yaitu dengan mempertanyakan pada diri peneliti sendiri 'mengapa musik terdengar seperti itu dan mengapa hal itu terjadi'. 'Suara' atau sudut pandang pelaku, termasuk penyanyi perempuan, atas tindakan mereka dalam mereproduksi lagu secara berbeda tidak didengar atau dimunculkan ke permukaan.

\section{Pembahasan}

\section{Pengetahuan dan Konstruksi Subjektivitas}

Di masa kecilnya, Ubiet sering menyaksikan pertunjukan kesenian tradisional yang dilakukan seniman lokal di daerah itu atau sekitarnya. Ia menceritakan pengalaman-pengalaman di masa kecilnya di Pidie (Aceh) dalam menyaksikan pertunjukan kesenian tradisional, misalnya tari Seudati ${ }^{6}$. Tidak hanya pertunjukan tradisional Aceh, Ubiet juga seringkali mendengar karya-karya sastra lokal, misalnya hikayat, yang diceritakan oleh nenek dari keluarga ayahnya. Pengalaman-pengalaman dalam menyaksikan dan mendengar beragam seni pertunjukan atau musik tradisional, khususnya musik Aceh, yang diperoleh pada masa kecil dapat dipandang sebagai salah satu bentuk pembelajaran non-formal yang terjadi dalam proses kehidupan Ubiet di

\footnotetext{
${ }^{6}$ Kata Seudati berasal dari bahasa Arab, syahadati atau syahadatain, yang berarti kesaksian atau pengakuan. Selain itu, ada pula yang mengatakan bahwa kata Seudati berasal dari kata 'seurasi' yang berarti harmonis atau kompak. Seudati mulai dikembangkan sejak agama Islam masuk ke Aceh. Penganjur Islam memanfaatkan tarian ini sebagai media dakwah untuk mengembangkan ajaran agama Islam. Tarian ini cukup berkembang di Aceh Utara, Pidie, dan Aceh Timur (Sumber: http://aamovi.wordpress.com/2009/04/01/sejarah-tari-seudati-aceh/)
} 
lingkungan sosialnya, khususnya di Sabang, Aceh. Selain dekat dengan musik tradisional, sejak kecil Ubiet juga telah mempelajari musik klasik Barat, khususnya piano.

Ketika memasuki perguruan tinggi, Ubiet memilih untuk mengikuti pendidikan musik di Institut Kesenian Jakarta (IKJ), Jakarta. Di lembaga pendidikan formal tersebut Ubiet mempelajari teknik vokal klasik Barat yang menekankan pada teknik bel canto $^{7}$. Kenyataannya, Ubiet tetap melakukan aktivitas musiknya dalam menyanyikan dan memainkan musik pop bersama kelompoknya, Splash Band. Keinginannya untuk mengeksplorasi suaranya muncul ketika ia merasakan kebosanan dalam mempelajari vokal Barat dan menyanyikan lagu-lagu pop. Ubiet kemudian tertarik dengan vokal tradisional serta banyak belajar dan mendengar pertunjukan-pertunjukan musik tradisional. Bahkan untuk memenuhi ketertarikannya untuk mengeksplorasi suara, Ubiet sering mengimitasi beragam bunyi yang ia dengar.

Keinginannya untuk terus mengeksplorasi suara dan mendalami musik tradisional menjadi dasar keputusannya untuk meneruskan pendidikan formal di bidang etnomusikologi di University of Wisconsin, Madison (USA) pada tingkat S2 dan S3. Dalam masa pendidikan, Ubiet seringkali melakukan penelitian-penelitian tentang musik dalam masyarakat lokal. Seluruh pengetahuan yang diperoleh dan didukung oleh beragam pengalaman musikal akhirnya membentuk suatu gaya bernyanyi yang diinginkan Ubiet. Penemuan gaya bernyanyi tersebut diperoleh selama \pm 20 tahun masa pencarian, yaitu gaya nyanyi berornamen yang bertolak dari warna lokal. Gaya bernyanyi tersebut selalu digunakan Ubiet dalam mereproduksi lagu-lagu dari beragam genre musik dalam berkolaborasi dengan musisi dan/atau komponis, tetapi juga dengan banyak seniman di bidang seni tari, teater, visual, maupun grafis.

Berdasarkan uraian di atas maka dapat dikatakan bahwa seluruh pengalaman yang diperoleh Ubiet secara formal maupun non-formal secara gradual membentuk pengetahuan dan wawasan kultural atau habitus-nya. Pierre Bourdieu (1990) menjelaskan bahwa habitus merupakan " a system of durable, transposable dispositions which functions as the generative basis of structured, objectively unified practices".

\footnotetext{
${ }^{7}$ Owen Jander pada tulisannya, Bel Canto: Fine Singing (dalam Sadie, 1995), menjelaskan bahwa teknik bel canto umumnya dipahami sebagai teknik yang mengindikasikan gaya vokal Itali yang elegan pada abad ke-18 dan awal abad ke-19.
} 
Pengetahuan penyanyi perempuan dapat dipandang sebagai praktik kultural yang diperoleh dari hasil pendidikan formal maupun non-formal. Selanjutnya, Bourdieu (1994) menjelaskan bahwa:

... all cultural practices (museum visits, concert-going, reading, etc.), and preferences in literature, painting or music, are closely linked to educational level (measured by qualifications or length of schooling) and secondarily to social origin. The relative wieght of home background and of formal education (the effectiveness and duration of which are closely dependent on social origin) varies according to the extent to which the different cultural practices are recognized and taught by the educational system, and the influence of social origin is strongest - other things being equal - in 'extra-curricular' and avant-garde culture.

Seluruh praktik kultural dan pilihan-pilihan dalam literatur, lukisan atau musik sangat berkaitan dengan tingkat pendidikan dan lingkungan sosial. Tingkat keterkaitan antara pengetahuan yang diperoleh secara non-formal dan formal bervariasi, tergantung pada tingkat praktik kultural yang berbeda diperkenalkan dan diajarkan melalui sistem pendidikan atau sekolah. Berdasarkan pernyataannya itu Bourdieu meyakini bahwa asal-usul sosial memiliki pengaruh yang paling kuat pada pengetahuan seseorang.

Pengetahuan yang dimiliki Ubiet pada akhirnya membentuk kompetensi khusus atau kemahiran estetik tertentu. Kemahiran estetik tersebut tidak hanya bergantung pada pendidikan formal saja, tetapi lebih pada banyaknya aktivitas musik yang ia lakukan. Pendidikan formal dipandang hanya dapat memberikan konsep-konsep yang dibutuhkan untuk analisis dan klasifikasi karya seni, tetapi tidak dapat memberikan kompetensi khusus atau 'kemahiran' estetik (connoisseur), misalnya gaya bernyanyi. Bourdieu (1994) menjelaskan kompetensi spesifik atau 'kemahiran’ estetik sebagai berikut:

The competence of the 'connoisseur', an unconscious mastery of the instruments of appropriation which derives from slow familiarization and is the basis of familiarity with works, is an 'art', a practical mastery which, like an art of thinking or an art of living, cannot be transmitted solely by precept or prescription. Learning it presupposes the equivalent of the prolonged contact between disciple and master in a traditional education, i.e., repeated contact with cultural works and cultured people.

Menurut Bourdieu, seperti halnya dengan seni berpikir atau seni hidup, kompetensi khusus atau kemahiran estetik merupakan 'seni', yaitu penguasaan praktik 
yang tidak dapat diajarkan hanya melalui sistem pendidikan atau sekolah. Kemahiran estetik ini hanya dapat diperoleh melalui kebiasaan melakukan pengalaman-pengalaman konkrit secara terus-menerus dengan budaya yang sah dan orang-orang yang memiliki budaya itu. Pemikiran Bourdieu tersebut sejalan dengan Richard Miller (1996) yang pernah menyatakan bahwa, "artistry in singing is acquired by practice (habit) just as is technique". Sama halnya dengan teknik bernyanyi, keartistikan dalam bernyanyi diperoleh dari kebiasaan melakukan aktivitas praktik secara terus-menerus. Kemahiran estetik atau gaya bernyanyi yang artistik secara gradual akan menjadi identitas musikal bagi penyanyi yang melakukannya. Dengan dimilikinya identitas musikal tertentu, seorang penyanyi akan dapat me(re)konstruksi subjektivitasnya dalam pertunjukan musik atau musik populer.

Pertunjukan musik seolah-olah menjadi tempat atau arena bagi penyanyi sebagai 'agen yang bebas' untuk merealisasikan tujuannya, yaitu memperlihatkan subjektivitasnya yang berbeda dari penyanyi yang lain, baik perempuan maupun lakilaki. Chris Barker (2000) menjelaskan bahwa subjektivitas mengacu pada:

condition of being a person and the processes by which we become a person, that is, how we are constituted as subjects. As subjects, that is, as persons, we are 'subject to' social processes which bring us into being as 'subjects for' ourselves and others.

Kondisi menjadi seseorang (person) dan proses-proses menjadi seseorang adalah bagaimana kita dipandang sebagai subjek. Sebagai subjek atau seseorang, kita adalah 'subjek pada' proses-proses sosial yang menjadikan kita sebagai 'subjek bagi' diri kita sendiri dan orang lain. Mempertanyakan subjektivitas berarti mempertanyakan "apakah subjek?". Untuk menjadi subjek, seseorang harus dapat diidentifikasi berbeda dari orang lain. Mengikuti pemikiran Barker tersebut maka dapat dikatakan bahwa agar dapat diidentifikasi sebagai subjek dalam pertunjukan musik, seorang penyanyi akan menggunakan pengetahuan dan kemahiran estetiknya untuk bernegosiasi dengan ruang dan waktu. Salah satu upaya penyanyi untuk me(re)konstruksi subjektivitasnya dalam pertunjukan musik adalah suara yang diproduksi melalui gaya bernyanyi tertentu.

Berdasarkan pemaparan di atas dapat dikatakan bahwa subjektivitas terbentuk dalam pertunjukan musik. Judith Butler (dalam Fenstermaker dan West, 2000; Salih, 2002) pernah menegaskan bahwa “..., subjectivity, and identity, ..., are constituted in 
and performatively produced (and reproduced) through discourse". Mengikuti pemikiran Butler tersebut dapat dikatakan bahwa subjektivitas dibentuk dalam dan diproduksi (dan direproduksi) secara performatif melalui wacana, termasuk pertunjukan musik.

\section{Reproduksi Lagu Kr. Kemayoran dan Konstruksi Subjektivitas}

$K r$. Kemayoran merupakan salah satu lagu keroncong yang direproduksi oleh Ubiet dalam album rekamannya, Ubiet: Kroncong Tenggara (Ragadi Musik, 2007). Aransemen seluruh lagu dalam album tersebut dilakukan atas kerjasama Ubiet dengan musisi pop (Dian HP) dan jazz (Riza Arshad). Lirik yang digunakan Ubiet dalam lagu ini adalah sebagai berikut:

\section{KR. KEMAYORAN}

La la la la la la la la o.... darimana datangnya lintah Jiwa manis indung disayang... la la la la la la la la o.... Darilah sawah, darilah sawah turun ke kali

Darimana datangnya cinta, darilah mata turun ke hati $(2 \mathrm{x})$

La la la la la la la la o....kalau ada sumur di ladang Jiwa manis indung disayang... la la la la la la la la o.... Bolehlah saya, bolehlah saya menumpang mandi

Kalau ada lelangit lapang, bolehlah punai melayang pergi Kalau ada sungai memanjang, bolehkah saya bersayang lagi

Kalau ada serai di ladang, bolehlah surya bersinar lagi Kalau ada punai melayang, bolehkah saya terus menyanyi

Ubiet, Dian H.P. dan Riza Arshad melakukan pengembangan pada lagu tersebut tanpa menghilangkan sama sekali karakter keroncong itu sendiri. Melodi yang dinyanyikan oleh Ubiet adalah: 


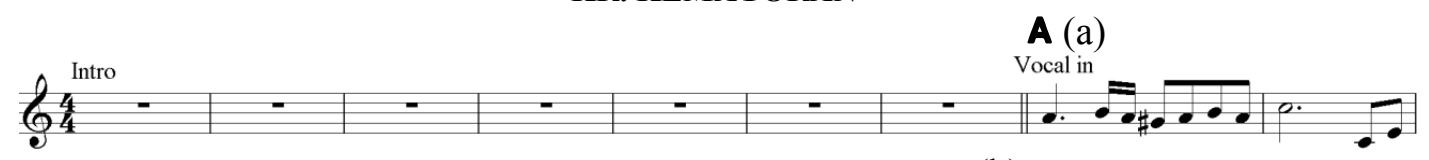

(b)
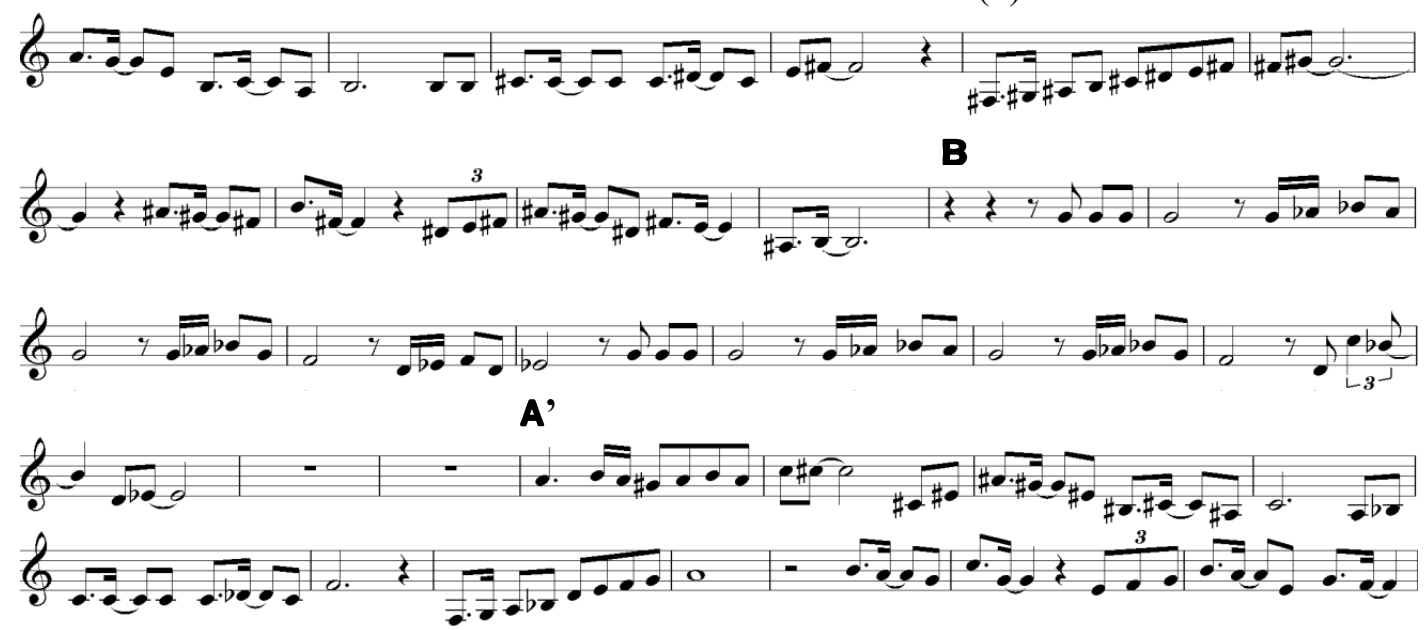

B'
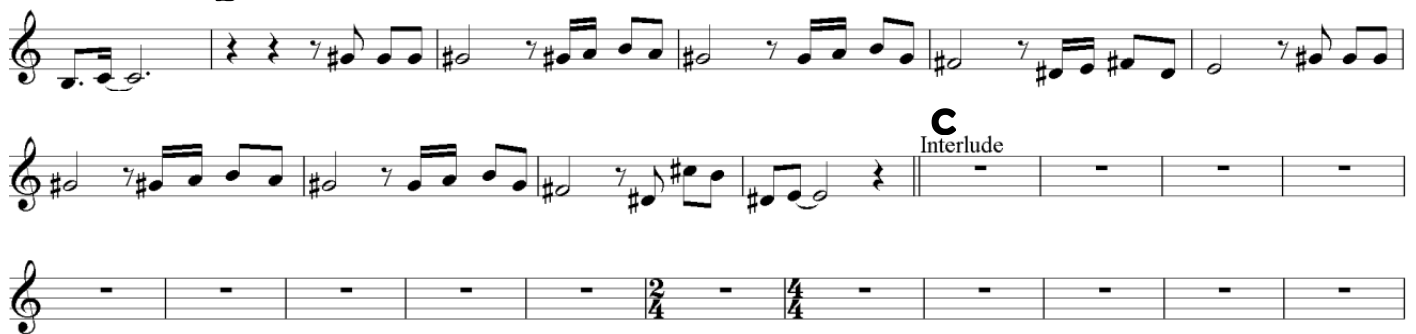

B'

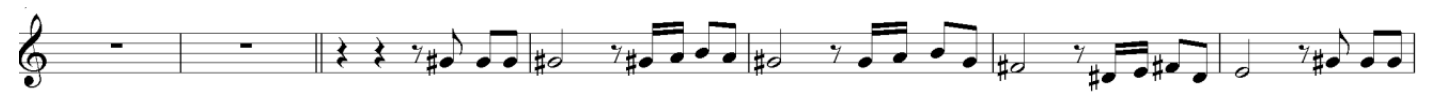

\section{Coda}
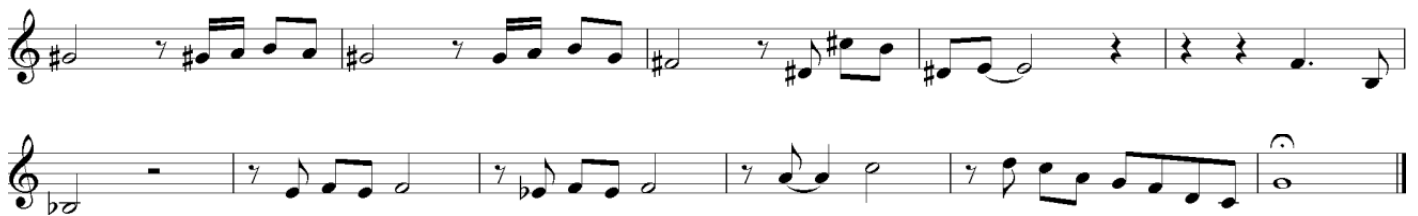

Gambar 2:

Transkripsi bagian vokal pada lagu Kr. Kemayoran versi Ubiet

(Transkripsi penulis)

Secara umum, reproduksi lagu ini memiliki struktur: Intro - A $-\mathbf{B}-\mathbf{A}^{\prime}-\mathbf{B}$ ' - C (Interlude) - B' - Coda. Secara keseluruhan, yang paling nampak unik dalam karya ini adalah penggunaan beberapa modulasi yang sangat "mengganggu" melodi 
utama yang terdapat pada vokal. Perpindahan tonalitas atau modulasi itu adalah A minor - C Mayor - B Mayor - E ${ }^{\supset}$ Mayor - C Mayor - B ${ }^{b}$ Mayor - E Mayor.

Bagian A (bar 8 - 19) terdiri dari 2 bagian kecil, yaitu bagian a (bar 8 - 13) dan b (bar 14 - 19). Pada bagian a saat vokal masuk, kesan tonalitas yang terdengar adalah minor yang disebabkan oleh musik pada bagian intro. Hal ini sangat berbeda dari versi $K r$. Kemayoran yang biasanya dinyanyikan oleh penyanyi keroncong. Berbeda dari versi umum yang menggunakan nada do pada awal lagu, Ubiet menggunakan nada la sebagai awal vokal (bar 8) sehingga lagu terkesan minor (dalam tonalitas A minor). Namun, interval dalam urutan nada selanjutnya sama persis dengan versi umum, yaitu sekon Mayor atau minor. Pada bar 2, Ubiet justru mempertahankan nada C5, sama dengan versi umum.

\section{Versi Ubiet:}

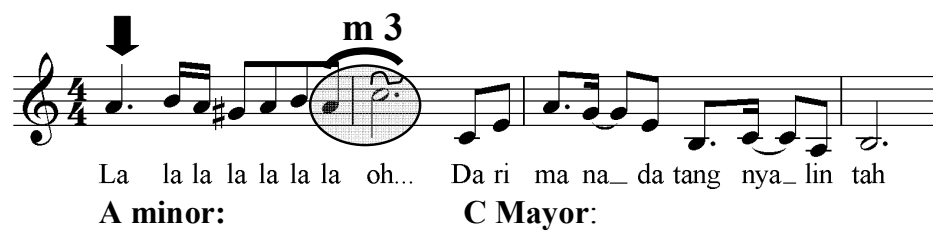

Versi umum:

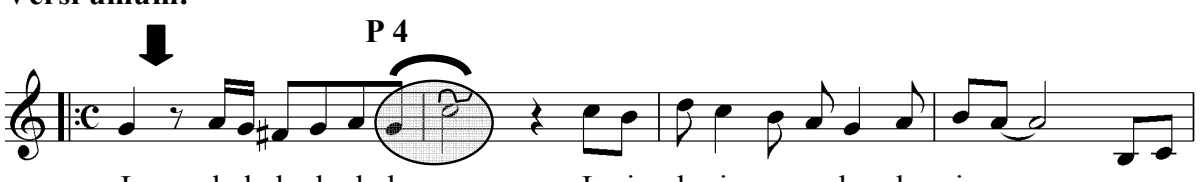

La la la la la la la o..... La-ju la- ju pe-ra-hu la - ju......

C Mayor:

\section{Gambar 3:}

Awal lagu Kr. Kemayoran versi Ubiet dan umum

(Transkripsi penulis)

Sebagai dampaknya, interval antara nada terakhir bar 8 (A4) dan nada awal bar 9 (C5) adalah terts minor (m3) yang berbeda dari versi umum, yaitu interval kuart perfect (P4). Pada hitungan ke-4 dalam bar 9 hingga awal bar 10, Ubiet menyanyi dalam tonalitas $\mathrm{C}$ Mayor, sama dengan versi umum.

Ubiet kembali mengikuti modulasi yang dimainkan oleh instrumen pada bar 12 - 13, yaitu dalam B Mayor, dengan didahului oleh melodi yang bergerak dari nada B ke nada $C$ dan dilanjutkan ke nada berikutnya. Perpindahan tonalitas tersebut dilakukan dengan sangat halus sehingga tidak terlalu jelas terdengar. 


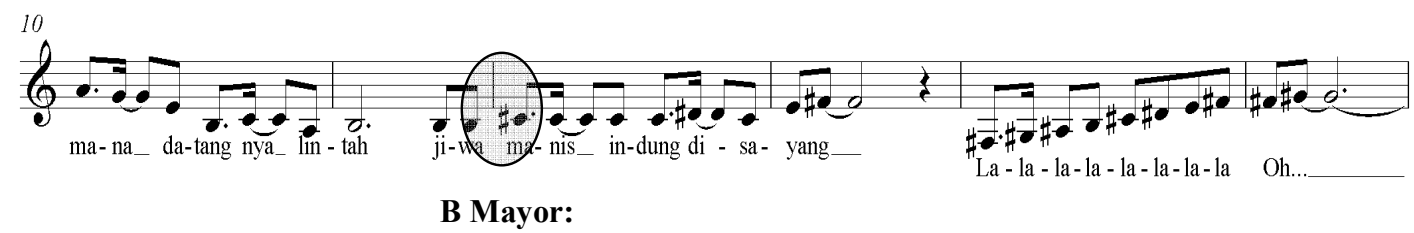

Gambar 4:

Bar 12 - 13 dalam tonalitas B Mayor

(Transkripsi penulis)

Pada bagian b (bar 14 - 19), Ubiet kembali mengikuti perubahan tonalitas ke Eb Mayor yang diawali oleh musik pengiring yang secara singkat memainkan akor $\mathrm{B}^{b}$ Mayor. Akor ini berfungsi sebagai Dominan dalam tonalitas $\mathrm{E}^{b}$ Mayor. Tonalitas $\mathrm{E}^{\boldsymbol{b}}$ Mayor ini terus dipertahankan dalam bagian B (bar 20 - 30).

Fenomena awal pada bagian A' (bar 31 - 42) dapat dikatakan sama dengan awal bagian A, yaitu pada lirik "La.la la la la la la oh...". Apabila lirik "la oh" dalam bagian A merupakan urutan nada yang berinterval 3 minor (A4 - C5), dalam bagian A' urutan nada pada lirik tersebut adalah A4 - C5 dilanjutkan ke $C^{5}$ yang berinterval 1 Augmented atau 2 minor. Selain itu, terdapat perbedaan lain antara bagian $\mathbf{A}$ dan A'. Dalam bagian A, tonalitas lagu dimulai dari minor dan dilanjutkan ke C Mayor, sedangkan dalam bagian $\mathbf{A}^{\prime}$ dimulai dengan tonalitas minor yang dilanjutkan ke $\mathbf{C}$ Mayor. Selanjutnya terjadi proses modulasi kembali ke tonalitas $\mathrm{B}^{b}$ Mayor.

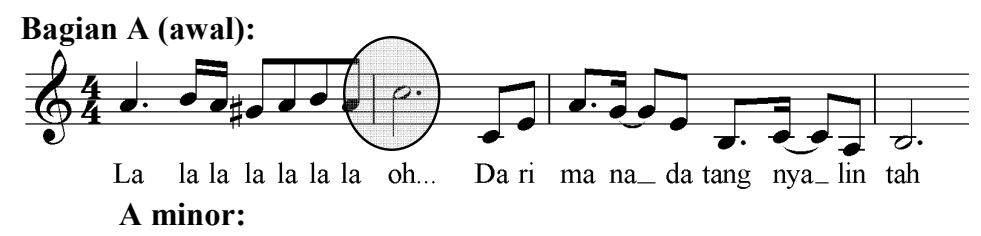

Bagian A' (awal):

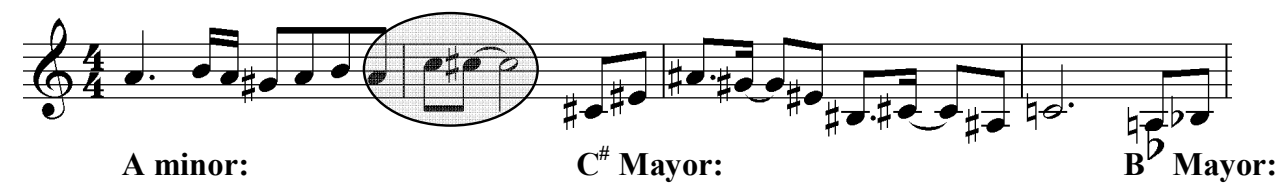

Gambar 5:

Perbandingan melodi pada bagian A (awal) dan A' (awal)

(Transkripsi penulis) 
Urutan melodi dalam bagian B' (bar 43 - 51) sama dengan urutan nada dalam bagian B. Perbedaannya hanya dalam penggunaan tonalitas. Tonalitas pada bagian B adalah $\mathrm{E}^{\text {b }}$ Mayor, sedangkan tonalitas dalam bagian B' adalah E Mayor. Bagian C (Interlude) merupakan bagian untuk musik pengiring. Bagian B' kembali muncul dan tidak ada perubahan pada urutan melodinya. Perbedaan hanya pada teks yang digunakan. Bagian Coda (bar 78 - 84) merupakan bagian penutup lagu. Dalam bagian ini Ubiet menyanyikan melodi yang kadang-kadang memiliki nada yang sama dengan nada yang dimainkan oleh flute.

Reproduksi lagu Kr. Kemayoran yang dilakukan atas kerjasama Ubiet, Dian HP, dan Riza Arshad ini tidak hanya dengan melakukan perubahan tonalitas atau modulasi, tetapi juga melakukan perubahan metrum, yaitu dalam metrum ( $\underset{\mathbf{4}}{\mathbf{4}}$ dan $\underset{\mathbf{4}}{\mathbf{2}})$ yang dimainkan oleh musik pengiring pada bar ke 60 - 61. Hal ini merupakan kesulitan tersendiri bagi penyanyi keroncong yang terbiasa menyanyikan versi umum, yaitu hanya bernyanyi dalam satu metrum $(\mathbf{4})$.

Selain itu, dalam lagu ini Ubiet juga menggunakan wilayah suaranya yang luas, khususnya dalam mencapai nada $F^{2}$, seperti tampak pada bar 13 .

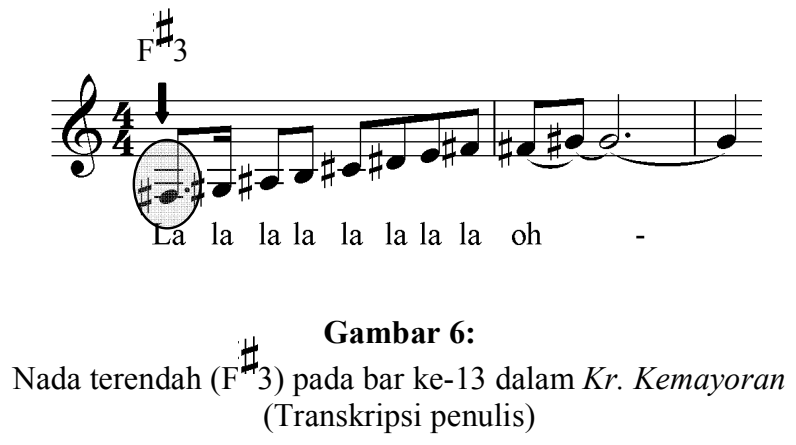

Sebagai seorang penyanyi berjenis suara sopran, menyanyikan nada $\mathrm{F}_{3}$ memperlihatkan kemampuannya untuk mencapai nada terendah dalam wilayah suara penyanyi alto.

Perubahan yang dilakukan Ubiet, Dian HP, dan Riza Arshad dalam mereproduksi lagu-lagu keroncong bukan berarti merombak 'aturan-aturan' dalam musik keroncong secara utuh. Walaupun membuat perubahan atau 'kejutan' dalam musik keroncong, Ubiet tidak menghilangkan sama sekali ciri khas yang umumnya 
dilakukan oleh penyanyi keroncong, yaitu ornamen, seperti cengkok dan nggandul ${ }^{8}$. Namun, dalam menyanyikan lagu ini Ubiet menerapkan banyak cengkok yang memiliki interval-interval kecil yang dilakukan pada setiap nada panjang. Penerapan cengkok tersebut dipandang berbeda dari cengkok yang digunakan oleh penyanyi keroncong lainnya.

Hampir sama dengan cengkok, penonton ada yang memandang bahwa Ubiet menggunakan nggandul atau menggantung ketukan atau maat secara berbeda dari penyanyi keroncong lainnya. Ubiet menggunakan nggandul hampir sesuai dengan ketukan. Perbedaan antara Ubiet dengan penyanyi keroncong dalam menggunakan nggandul ketika menyanyikan lagu-lagu keroncong adalah Ubiet menyanyikan ritmik lagu ini secara lebih teratur, yang justru dipandang kurang alami oleh penonton yang terbiasa mendengar lagu-lagu keroncong.

Ubiet mengakui bahwa ornamen yang ia gunakan berbeda dari penyanyi keroncong umumnya. Mengenai kenyataan ini, Ubiet menjelaskan, "aku hanya menyanyikan lagu-lagu keroncong. Aku hanya meminjam. Aku bukan penyanyi keroncong". Ubiet memandang bahwa caranya mereproduksi lagu ini secara berbeda bukan suatu masalah. Menurutnya, dalam seni dikenal istilah manipulasi, yaitu melakukan perbedaan dari yang pernah ada.

Tentu saja ada ornamen. Keroncong itu sangat dikenali melalui ornamenornamennya, baik instrumentasinya maupun cara nyanyinya. Kalau dianalisa pasti kelihatan. Ada ornamen yang berpengaruh. Jadi, aku bukan keroncong lagi... Formasi akor saja sudah ada perkembangan... Kesenian harus begitu...Kalau gak berbeda, apa bedanya dengan kehidupan sehari-hari. Panggung harus beda dari hidup sehari-hari. Kesenian kan manipulasi, yaitu, bagaimana kita mengolah bahan menjadi sesuatu yang berbeda dari yang sehari-hari. ${ }^{9}$

\section{Penutup}

Subjektivitas penyanyi perempuan tidak hanya dapat dikonstruksi melalui representasi tubuh, tetapi juga pada reproduksi suara yang dihasilkan melalui gaya bernyanyi tertentu. Konstruksi subjektivitas penyanyi perempuan tidak hanya

\footnotetext{
${ }^{8}$ Harmunah dalam bukunya Musik Keroncong: Sejarah, Gaya, dan Perkembangan (1987), menjelaskan bahwa nggandul merupakan istilah dalam Bahasa Jawa yang berarti menggantung atau menahan ketukan irama lagu. Cengkok ialah segala bentuk nada hiasan yang mengembangkan kalimat lagu, yang berarti mengisi, memperindah, dan menghidupkan kalimat lagu

9 Wawancara pada 14 Juli 2010.
} 
didasarkan pada pengetahuan yang diperoleh secara formal, tetapi lebih pada kompetensi khusus atau kemahiran estetik yang diperoleh secara gradual dari beragam pengalaman praktik yang secara terus-menerus dilakukan dalam proses kehidupannya di lingkungan sosial. Kemahiran estetik Nyak Ina Raseuki (Ubiet) di antaranya adalah wilayah suaranya yang sangat luas, kemampuan menyanyikan nada-nada dengan interval kecil (microtone), menerapkan ornamen-ornamen keroncong (cengkok dan nggandul) sebagai upaya untuk tetap menjaga karakter keroncong, memadukan unsur keroncong dengan genre musik yang lain, dan kemampuan untuk mengikuti perubahanperubahan, misalnya perubahan tonalitas (modulasi) dan metrum, yang didahului oleh pengiring. Kemahiran estetik tersebut secara langsung mengkonstruksi subjektivitas Ubiet yang berbeda dari penyanyi keroncong lainnya, baik laki-laki maupun perempuan.

\section{Kepustakaan}

Abdullah, Irwan. 2003. Seks, Gender, dan Reproduksi Kekuasaan. Yogyakarta: Tarawang Press.

Barker, Chris. 2000. Cultural Studies: Theory and Practice. London: SAGE Publication,

Bourdieu, Pierre. 1977. Outline of a Theory of Practice. Cambridge: Cambridge University Press.

. 1994. Distinction: A Social Critique of the Judgement of Taste. London: Routledge.

Brooks, Ann. 1997. Posfeminisme dan Cultural Studies: Sebuah Pengantar Paling Komprehensif. Terjemahan oleh S. Kunto Adi Wibowo. Yogyakarta: Jalasutra.

Fenstermaker, Sarah dan Candace West (eds.). 2002. Doing Gender, Doing Difference: Inequality, Power, and Institutional Change. New York dan London: Routledge.

Jander, Owen. 1995. "Bel Canto: Fine Singing”. Dalam Sadie, Stanley (ed.). The New Grove: Dictionary of Music and Musicians Vol. 2. New York: Macmillan Publishers Ltd.

Jarman-Ivens, Freya, 1983 - 2003. "What It Feels Like for Two Girls: Madonna's Play with Lesbian (Sub-) Cultures", dalam Santiago, Fouz-Hernandez dan Freya Jarman-Ivens (eds.), Madonna's Drowned Worlds: New Approaches to Her Cultural Transformations.

Håkensen, Tonje. diunduh pada 20 Juli 2008. “Don’t You Realize It's Just Her Disguise?": Performances of Femininity by Kim Gordon, Tori Amos, and 
Gillian Welch". Tesis untuk meraih derajat Magister Bidang Musikologi, Institute of Musicology, University of Oslo, 2007. Sumber: http://www.duo.uio.no/publ/IMV/2007/52209/Tonje Hxkensen_masterthesis [1].

Harmunah. 1987. Musik Keroncong: Sejarah, Gaya, dan Perkembangan. Yogyakarta: Pusat Musik Liturgi.

Humm, Maggie. 2002. Ensiklopedia Feminisme. Terjemahan oleh Mundi Rahayu. Yogyakarta: Fajar Pustaka Baru.

Marshall, Catherine dan Gretchen B.Rossman. 2006. Designing Qualitative Research. Thousand Oaks: SAGE Publications.

Miller, Richard. The Structure of Singing. 1996. Belmont CA: Wadsworth Group/Thomson Learning.

Moore, Allan F (ed.). 2003. Analyzing Popular Music. Cambridge: Cambridge University Press.

O'Shea, Helen Vol. 17, No. 1/2008. "Good Man, Mary!' Women Musicians and the Fraternity of Irish Traditional Music". (sebuah artikel dalam Journal of Gender Studies, ).

Salih, Sarah. 2002. Judith Butler. New York: Routledge.

Santiago, Fouz-Hernandez dan Freya Jarman-Ivens (eds.), 2004. Madonna's Drowned Worlds: New Approaches to Her Cultural Transformations, 1983 - 2003 (Aldershot: Ashgate).

Ubiet: Penyanyi Langka di Belantara Pop. diunduh pada 15 Agustus 2009. Selebriti dalam Newsmusik Edisi 13/2000.

Whiteley, Sheila. 2000. Women and Popular Music: Sexuality, Identity, and Subjectivity. New York: Routledge. 